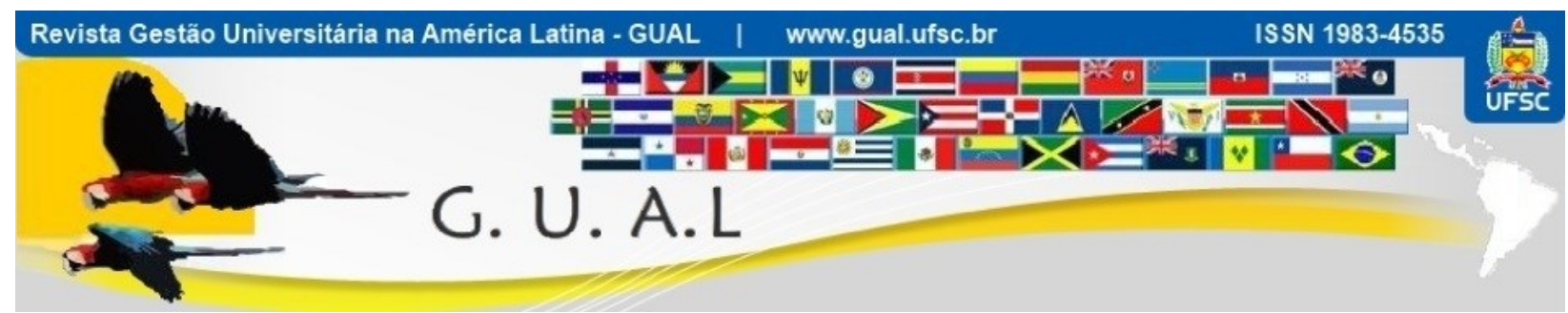

DOI: http://dx.doi.org/10.5007/1983-4535.2016v9n1p1

\title{
UNIVERSIDADES PRIVADAS E O ENADE: QUAL CATEGORIA ADMINISTRATIVA TEM MELHOR DESEMPENHO NO CURSO DE ADMINISTRAÇÃO
}

\author{
PRIVATE UNIVERSITIES IN BRAZIL AND THE PERFORMANCE OF THE \\ STUDENTS (ENADE): WHICH ADMINISTRATIVE CATEGORIES HAS BETTER \\ RESULTS IN UNDERGRADUATE MANAGEMENT COURSES
}

\author{
Adriana Amadeu Garcia Torres, Doutoranda \\ Universidade do Grande Rio - Unigranrio \\ adriana.amadeu.garcia@gmail.com
}

Paulo Cesar de Albuquerque Macedo, Mestre Universidade do Grande Rio - Unigranrio pcamacedo@uol.com.br

Alexandre Mendes Nicolini, Doutor Universidade do Grande Rio - Unigranrio alexandrenicolini@hotmail.com

Rui Otávio Bernardes de Andrade, Doutor Universidade do Grande Rio - Unigranrio andrade@novanet.com.br

Evandro de Campos Câmara, Bacharel Universidade do Grande Rio - Unigranrio evandrocamposc@outlook.com

Recebido em 18/junho/2014

Aprovado em 21/outubro/2015

Sistema de Avaliação: Double Blind Review

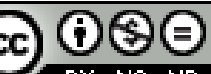

Esta obra está sob uma Licença Creative Commons Atribuição-Uso. 


\title{
RESUMO
}

Em função da mercantilização do ensino superior, e do espaço conquistado pelas universidades privadas neste cenário, o presente artigo tem como objetivo identificar, dentre as universidades privadas, qual a categoria administrativa - com fins lucrativos, sem fins lucrativos ou especial - que apresenta melhor desempenho no Enade. Para tanto, foram considerados os resultados nas três edições do Enade (2006, 2009 e 2012) das universidades privadas que oferecem o curso de bacharelado em Administração. A pesquisa foi descritiva e o levantamento de dados realizado com base em pesquisa bibliográfica. A base de dados disponibilizada pelo Inep foi de fundamental importância para se responder à questão levantada, desenvolvendo um trabalho de natureza quantitativa. Os resultados demonstram que os cursos ofertados em Instituições de Ensino Superior (IES) sem fins lucrativos têm avaliações superiores às suas congêneres que visam ao lucro, principalmente se elas forem filantrópicas ou confessionais.

Palavras-Chave: Avaliação. Universidade. Enade. Curso de Administração.

\begin{abstract}
Faced with the new reality of higher education in Brazil, where the attempt to meet the demand for training brings a new public to the university with a greater participation of private initiative, this article aims to identify in which administrative category (with or without profit or special) the private university has the best performance in the Enade. For results were considered universities that offer graduation in Administration and that participated the three editions of the Enade: 2006, 2009 and 2012. The research is descriptive and bibliographic. The basis of data provided by Inep was of fundamental importance to answer the question raised by developing a work of quantitative resource. The results of the category without profit is better than the with profit, especially if they are philanthropic or confessional.
\end{abstract}

Key-words: Evaluation. University. Enade. Management courses. 


\section{INTRODUÇÃO}

Foi na década de 90 que se intensificou o processo de mercantilização do ensino superior, a partir das novas legislações sancionadas em 1995, 1996 e 1999, e que buscavam dar maior autonomia ao setor (O ENSINO..., 2011, p. 2) em um período caracterizado por políticas de privatizações e desregulamentações, favorecendo o crescimento das Instituições de Ensino Superior (IES) privadas (SÉCCA; LEAL, 2009, p.114). Em dados absolutos, segundo Semerj (2015, p. 6), enquanto que, em 1993, das 873 IES, 652 eram da iniciativa privada; atualmente, das 2.391, 2.090 são instituições "que podem ser administradas por pessoas físicas ou jurídicas de direito privado, na forma prevista no Código Civil, com ou sem finalidade econômica ou lucrativa" (LDBE, BRASIL, 1996), e, não por acaso, são foco de estudos e pesquisas, como o proposto por este artigo.

No caso da universidade, por ter liberdade de criar cursos, inclusive fora da sede, e poder fixar o número de vagas oferecidas sem autorização prévia do governo (O ENSINO..., 2011, p.9), esta pôde atender a crescente demanda por vagas no ensino superior. Aliás, este privilégio tornou a universidade privada não apenas um negócio atraente para investimentos como terminou por criar condições para a atuação de empresas com capital aberto e para várias fusões e aquisições no setor (SÉCCA; LEAL, 2009, p.120-122). A universidade privada se posicionou como um tipo de instituição que tem hoje um papel decisivo na educação superior, que vem sendo "privilegiado com a redução de investimentos estatais nas IES públicas e pela autonomia concedida após a descentralização do poder da esfera estadual para as federais" (GARCIA; NICOLINI; ANDRADE, 2014, p. 26).

A universidade privada tem categorias administrativas especificadas por (1) com fins lucrativos, (2) sem fins lucrativos e (3) especial. Por assim dizer, "os aspectos financeiros são meios, e não fins da educação superior. Isso é o que ainda ocorre em algumas universidades mantidas por igrejas e comunidades e em outros estabelecimentos tradicionais" (O ENSINO..., 2011, p. 25). Três subcategorias vinculam-se à ausência de fins lucrativos: comunitária, confessional e/ou filantrópica. Neste caso, a referência é feita às "instituições que ainda preservam muito do sentido social e os valores da ciência e do conhecimento como valor público" (BRITTO ET AL, 2008, p. 782). Estas IES, ao invés de repassar ao governo os impostos como as demais empresas, têm obrigação de fazer investimentos em hospitais universitários, escolas e atendimento à população carente (O ENSINO..., 2011, p.11). 
No que tange à qualidade do que é ofertado, coube ao Ministério da Educação e Cultura "promover a efetivação da diretriz da qualidade no ensino superior. Para tanto, suas ações entre 2003 e 2010 basearam-se em três funções: avaliação, regulação e supervisão das instituições e cursos superior" (MEC, 2013, p. 2). Todavia, mesmo com a diversidade de índices qualitativos e quantitativos criados pelo Estado, "a aprendizagem dos estudantes continuou tendo um papel muito importante para a avaliação" (NICOLINI; ANDRADE; TORRES, 2013, p. 165).

Não por acaso, o Enade, prova realizada pelos estudantes, acabou recebendo destaque, chegando a ser utilizado para a criação de rankings e influenciando decisões dentro e fora das IES até os dias de hoje. E, exatamente por esta razão, o Enade será utilizado como parâmetro de avaliação neste estudo, que traz o seguinte questionamento: dentre as universidades privadas, qual a categoria administrativa que apresenta melhor desempenho no Enade?

Para tanto, serão considerados os resultados obtidos nas três edições do Enade (2006, 2009 e 2012) do curso de bacharelado em Administração, disponibilizados pelo Instituto Nacional de Estudos e Pesquisas Educacionais Anísio Teixeira (INEP, 2014). Assim, busca-se uma visão diferenciada das universidades privadas, distinguindo os resultados por categoria administrativa: com fins lucrativos, sem fins lucrativos e especial, em três subcategorias: comunitária, confessional e filantrópica.

\section{FUNDAMENTAÇÃO TEÓRICA}

Neste tópico serão apresentados os critérios que distinguem as categorias administrativas a que pertencem as Instituições de Ensino Superior, especialmente as Universidades Privadas, foco deste estudo. Em seguida, o Enade será explicitado como parâmetro de avaliação, de modo que se tenha o embasamento necessário para o desenvolvimento da pesquisa fruto de uma melhor compreensão do assunto estudado.

\subsection{AS CATEGORIAS ADMINISTRATIVAS DAS UNIVERSIDADES PRIVADAS NO BRASIL}

No Brasil, as instituições podem ser financiadas pelo Estado ou pela iniciativa privada. As públicas em princípio não cobram matrícula ou mensalidade e são mantidas pelos governos Federal, Estadual ou Municipal. Por outro lado, as de iniciativa privada cobram matrícula ou mensalidade e "podem ser administradas por pessoas físicas ou jurídicas de 
direito privado, na forma prevista no Código Civil, com ou sem finalidade econômica ou lucrativa" (LDBE, BRASIL, 1996).

Desta forma, "o financiamento no setor privado depende fortemente da cobrança de mensalidades, anuidades e taxas pelos cursos oferecidos (graduação, lato sensu, mestrado, doutorado, etc.)" (TANEGUTI, 2013, p.10), “desvinculando as negociações da área educacional e transferindo para os setores de relação com o consumidor e o produto consumido" (AMARAL, 2003, p. 104).

A participação das IES privadas na educação superior brasileira é expressiva, quando se considera o total de IES, segundo dados do Inep (2012) conforme pode-se visualizar no Gráfico 1. Vale ressaltar que o quantitativo apresentado considera todos os tipos de organização sem tratar as especificidades de cada uma.

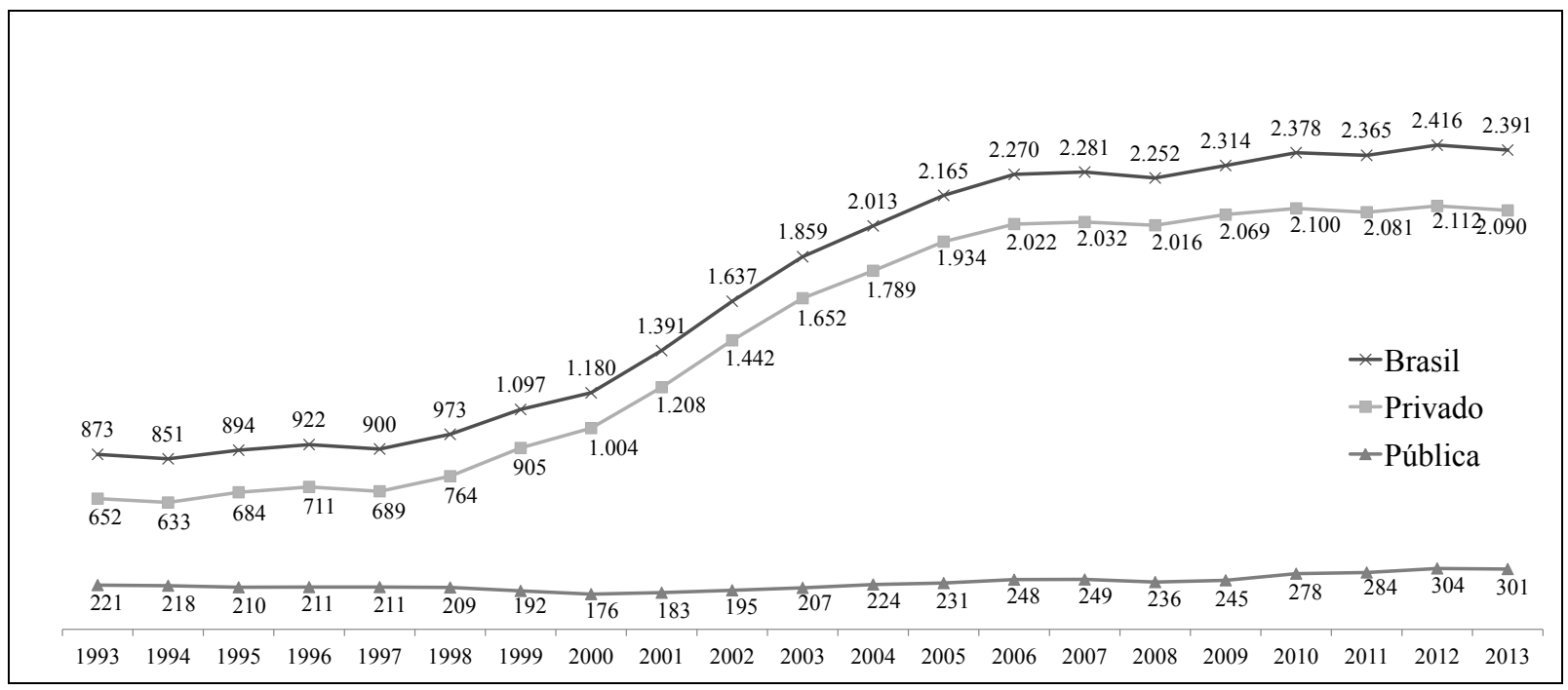

Gráfico 1 Quantidade de IES no Brasil por categoria administrativa.

Fonte: Semerj (2015, p. 6).

Todavia, deve-se entender que o grau de autonomia é conquistado gradativamente. Toda IES é credenciada inicialmente como faculdade, e em função do seu funcionamento regular e padrão de qualidade satisfatório pode alcançar o status de Centro Universitário, com autonomia na sede; ou, num padrão mais exigente de atividades de ensino, pesquisa e extensão, pode ser reconhecida como Universidade, podendo criar, organizar e extinguir cursos também fora da sua sede (BRASIL, 2006).

O presente estudo tem como foco as universidades privadas, que além da autonomia supramencionada, são "instituições acadêmicas pluridisciplinares que contam com produção intelectual institucionalizada, e apresentam requisitos mínimos de titulação acadêmica (um 
terço de mestres e doutores) e carga de trabalho do corpo docente (um terço em regime integral)" (DCE, 2014b). Este tipo de organização pode ser classificado em duas categorias administrativas, segundo o art. 20 da Lei $\mathrm{n}^{\circ}$ 9.394/96 da LDB: instituições com fins lucrativos e sem fins lucrativos; e três subcategorias, no caso das instituições sem fins lucrativos: comunitária, confessional ou filantrópica.

Uma terceira categoria administrativa, regulamentada pelo art. 242 da Constituição Federal, é a especial, “que considera uma instituição educacional oficial criada por lei estadual ou municipal e existente na data da promulgação da Constituição Federal, que não seja total ou preponderantemente mantida com recursos públicos, portanto não gratuita" (DCE, 2014a). Neste caso, vale ressaltar que o fato de apresentarem participação do governo, mas com controle da iniciativa privada, possibilita um enquadramento em qualquer das subcategorias específicas das instituições sem fins lucrativos.

Portanto, considerando tanto o art. 20 da Lei $\mathrm{n}^{\circ}$ 9.394/96 da LDB quanto o art. 242 da Constituição Federal, são três as categorias administrativas que podem ser classificadas as universidades privadas, conforme apresentado na Figura 1. A seguir, serão apresentados os critérios e aspectos marcantes em cada caso.

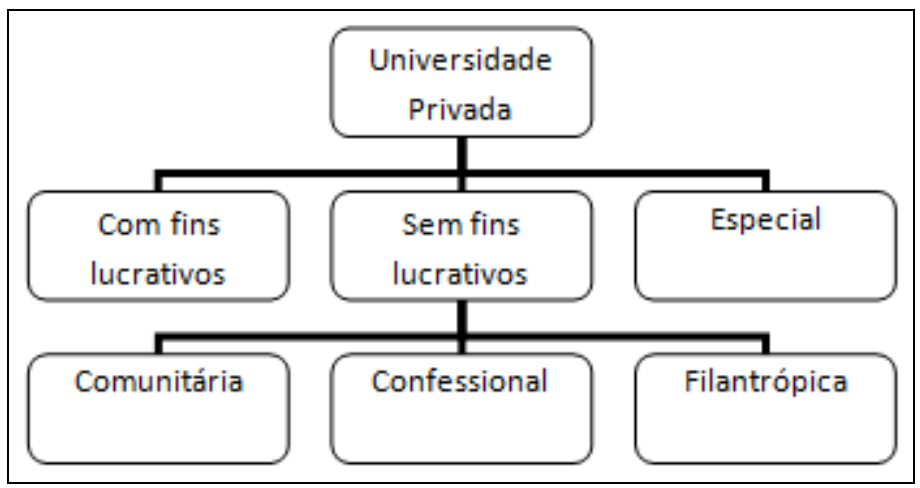

Figura 1 Categorias Administrativas das Universidades Privadas no Brasil.

"As Instituições com fins lucrativos ou particulares, em sentido stricto, são as mantidas e administradas por uma ou mais pessoas físicas ou jurídicas de direito privado" (O ENSINO..., 2011, p.11), tendo uma gestão compromissada com os retornos sobre os investimentos efetuados pelos proprietários capitalistas. Podem ser sociedades por cotas, sociedades anônimas, entre outras, e tem obrigação de apresentar as demonstrações financeiras atestadas por profissionais competentes em cada exercício social, segundo o art. $7^{\circ}$-D da Lei no 9.131/95 (BRASIL, 1995) incluído pela Lei no 9.870/99 (BRASIL, 1999). 
A universidade comunitária é uma instituição pertencente e dirigida por representantes de uma comunidade, que tem como objetivo final o desenvolvimento social da mesma (LIMA, 2009, p. 34). A Lei $\mathrm{n}^{0} 12.020$ de 2009 caracteriza estas instituições como sem fins lucrativos (FRAUCHES, 2012), e podem ser "instituídas por grupos de pessoas físicas ou por uma ou mais pessoas jurídicas, inclusive cooperativas de professores e estudantes" (TANEGUTI, 2013, p.6).

Em suma, desvinculadas administrativamente do Estado, as universidades comunitárias são criadas com a finalidade de atender às demandas de uma determinada comunidade. Possuem como características, além da participação dos interessados e da comunidade em sua administração, a constituição de um patrimônio público não-estatal...

(...) pois embora enquadradas na iniciativa privada, seu modelo não se iguala às instituições particulares e ou às instituições de cunho confessional. O patrimônio, por sua vez, é constituído de forma comunitária, logo, não está contido em nenhum patrimônio particular, ao contrário, diz respeito a um patrimônio público que é gerido pela instituição formada pela própria comunidade.(ARAUJO, 2010, p. 178)

Assim, a cobrança de mensalidade por parte da universidade privada comunitária, ao contrário da com fins lucrativos, não visa o lucro, mas sim o equilíbrio econômico-financeiro para sustentar suas atividades educacionais (LIMA, 2009, p. 37). Ainda assim, outras fontes de recursos não menos importantes, como isenções fiscais e previdenciárias e renúncia fiscal/PROUNI, além das fontes diretas como o FIES, fazem parte da estrutura financeira necessária à sobrevivência e manutenção destas instituições (TANEGUTI, 2013, p.10).

Outra subcategoria de universidades privadas sem fins lucrativos são "as confessionais, que nasceram da ação mais que centenária de instituições educacionais com práticas sociais originárias de sua vocação religiosa" (TAVARES, 2009, p.223). Conforme entendimento da LDB (art. 20 da Lei n 9.394/96), estas universidades são constituídas por grupos de pessoas físicas ou jurídicas com orientação confessional e ideológica específica. $\mathrm{Na}$ prática, "as instituições universitárias confessionais estão majoritariamente ligadas a grupos que confessam práticas religiosas e adotam em seus estatutos princípios que confessam sua crença dogmática” (LIMA, 2009, p. 25), sendo as Pontifícias Universidades Católicas (PUCs) as mais conhecidas (FRAUCHES, 2012).

A exemplo da universidade comunitária, as instituições confessionais também se diferenciam das particulares com fins lucrativos quanto aos objetivos dos resultados financeiros, não tendo como finalidade a obtenção de lucro para distribuição entre seus 
proprietários, mas sim o reinvestimento dos resultados positivos em suas finalidades estatutárias (TAVARES, 2012,p.70).

"As universidades filantrópicas são entidades reconhecidas pelo Poder Público, mediante ato específico, como de "utilidade pública" e devem aplicar, pelo menos, $20 \%$ de sua receita em beneficência, regendo-se por legislação específica" (FRAUCHES, 2012), prestando assim, serviços à população em atividades que complementam as obrigações do Estado com relação à educação (DCE, 2014b). Estas instituições podem ser classificadas também como comunitária ou confessional.

Para obter o status de filantrópica, a instituição deve possuir, obrigatoriamente, o Certificado de Assistência Social. Para tanto, se faz necessário, além de cumprir outras exigências requeridas pela lei $n^{\circ} 12.101 / 09$ (BRASIL, 2009), oferecer anualmente 20\% das matrículas em bolsas integrais para estudantes com renda familiar de até 1 salário-mínimo e meio ou promover ações assistenciais que contabilizem essa porcentagem.

\subsection{O ENADE COMO PARÂMETRO DE AVALIAÇÃO}

A proliferação de cursos de graduação no Brasil, se por um lado atende a demanda pela universalização da educação superior na sociedade; por outro, apresenta para o Estado desafios "para a democratização do acesso, para a articulação com as outras etapas da formação escolar e para o provimento de educação com qualidade" (DCE, 2014a).

No tocante ao quesito qualidade na formação superior, o governo procura desde a década de 90 formas de mensurar o desempenho dos cursos de graduação, especialmente em relação ao desenvolvimento das competências e habilidades esperadas como parâmetros mínimos à formação dos profisssionais. "Para tanto, instituiu e realizou sistematicamente a avaliação dos resultados obtidos por diversos cursos superiores em todas as áreas de conhecimento" (NICOLINI; ANDRADE; TORRES, 2013, p. 162).

O primeiro modelo de avaliação, o Exame Nacional de Cursos (ENC), foi criado em 24 de novembro de 1995 (Lei 9.131), no governo do presidente Fernando Henrique Cardoso, e tinha como proposta realizar avaliações periódicas da qualidade do ensino por meio de relatórios institucionais e visitação das IES, mas principalmente, por exames aplicados anualmente aos egressos dos cursos de graduação, exame este conhecido como Provão. Seu resultado era aferido por meio de conceitos de uma escala de A (excelente) até E (insatisfatório). 
Assim, "o Provão foi a primeira iniciativa com o objetivo de avaliar a qualidade do ensino superior aplicada de forma universal e obrigatória no Brasil" (VERHINE; DANTAS; SOARES, 2006, p. 294). Contudo, por manter o foco principal da avaliação no exame, em detrimento dos outros instrumentos de avaliação das IES "em termos do currículo, da qualificação docente, das instalações físicas e da biblioteca” (op. cit., p. 294), foi bastante criticado no meio acadêmico, mostrando-se incompleto como modelo. Aliás, algumas instituições chegaram a fazer treinamentos de egressos para a realização do provão, com o intuito de subir no ranking de resultados. (GARCIA; NICOLINI; ANDRADE, 2014, p. 28).

Com o objetivo de reformular o criticado sistema de avaliação do ensino superior vigente à época, o Provão, em 14 de abril de 2004, o então presidente Luís Inácio Lula da Silva cria o Sistema de Avaliação da Educação Superior (Sinaes), que "avalia todos os aspectos que giram em torno dos eixos: ensino, pesquisa, e extensão. São eles: a responsabilidade social, o desempenho dos estudantes, a gestão da instituição, o corpo docente, as instalações e vários outros aspectos" (INEP, 2014).

\footnotetext{
Sua finalidade é a melhoria da qualidade da educação superior, a orientação da expansão da sua oferta, o aumento permanente da sua eficácia institucional e efetividade acadêmica e social e, especialmente, a promoção do aprofundamento dos compromissos e responsabilidades sociais das instituições de educação superior, por meio da valorização de sua missão pública, da promoção dos valores democráticos, do respeito à diferença e à diversidade, da afirmação da autonomia e da identidade institucional (BRASIL, 2004).
}

“O Sinaes se baseia numa concepção de avaliação e de educação global e integradora. Mais que um simples instrumento isolado, busca construir um sistema nacional de avaliação da Educação Superior" (DIAS SOBRINHO, 2010, p. 208). Diferente do Provão, a proposta do Sinaes tem como base a existência de uma avaliação que não leve em consideração somente o exame realizado pelos estudantes, mas uma combinação de instrumentos utilizados em momentos e contextos diferentes, considerando a instituição como um todo. "Para tanto, utiliza-se da Avaliação Institucional da Avaliação das Condições de Ensino, do Censo da Educação Superior, do Cadastro da Educação Superior e do Exame Nacional de Desempenho dos Estudantes (Enade)" (NICOLINI; ANDRADE; TORRES, 2013, p. 165).

Apesar da concepção de um sistema de avaliação que procura mensurar a qualidade dos cursos de graduação das IES, por meio de uma composição de instrumentos que leva em consideração não apenas o desempenho dos estudantes, mas também o desempenho e a 
atuação das instituições e dos cursos, a avaliação da aprendizagem, por meio do Enade, continuou tendo um grande peso no resultado da avaliação.

O Enade lançou como objetivo principal aferir a aprendizagem dos estudantes nos conteúdos programáticos compreendidos nas diretrizes curriculares do seu curso de graduação, nas habilidades que deveriam ter sido desenvolvidas para fazer face aos problemas esperados pelos futuros profissionais e nas competências para perceber e compreender temas que são conexos ao seu âmbito profissional, ligados à realidade brasileira e mundial. (BRASIL, 2004).

Assim, segundo Verhine, Dantas e Soares (2006), as diferenças entre o Provão e o Enade são poucas. Os autores citam a mudança da frequência do exame, que antes era anual e agora é aplicado a cada três anos para o mesmo curso; e a utilização do Indicador de Diferença dentre os Desempenhos Observado e Esperado (IDD).

De acordo Bittencourt et al (2008) o IDD era a grande inovação do Sinaes, na medida em que ele representa uma resposta aos protestos das IES privadas quanto a situação de desequilíbrio existente entre o nível de formação do estudante que ingressa nas IES públicas, muito mais bem preparados do que o da rede privada. "Ao considerar os conhecimentos prévios de cada estudante, o IDD estabelece uma medida mais justa de checagem do "valor agregado" entre instituições teoricamente comparáveis" (NICOLINI; ANDRADE; TORRES, 2013, p. 167). De qualquer forma, este elemento não será utilizado pelo presente estudo.

Com relação ao resultado do Enade, parâmetro que irá embasar a análise desta pesquisa, o estudante após fazer o exame recebe um conceito que pode variar de 1 (pior desempenho) à 5 (melhor desempenho), sendo 3 considerado um desempenho satisfatório. Estes resultados são mantidos em sigilo e informados individualmente a cada estudante que realizou a prova. Para a IES é divulgado apenas o resultado geral com base nas notas dos seus estudantes que fizeram a prova.

Confirmando a premissa de que as instituições e cursos utilizariam os resultados verificados no atual sistema de avaliação da qualidade da educação superior, para consubstanciar um processo avaliativo institucional mais abrangente, o Inep instituiu o cálculo do Conceito Preliminar de Curso (CPC, BRASIL, 2008a) e do Índice Geral dos Cursos (IGC, BRASIL, 2008b), baseado nos dados produzidos pelo Enade em conjunto com as outras dimensões avaliativas previstas pelo Sinaes, o que reforça a importância do Enade como parâmetro de avaliação. 


\section{MÉTODO DE PESQUISA}

A presente pesquisa, de natureza quantitativa, tem caráter descritivo e foi desenvolvida com base em pesquisa bibliográfica, tendo sido consultadas Leis, Decretos e Portarias que regulamentam o funcionamento do ensino superior no Brasil.

Não obstante, os autores buscaram informações acerca dos órgãos envolvidos diretamente com o sistema de avaliação das IES e consideraram a base de dados disponibilizados pelo Inep (2014) em seu site referentes aos resultados das IES nas três edições do Enade: 2006, 2009 e 2012.

O universo é formado pelas universidades privadas que oferecem o curso de bacharelado em Administração e que participaram das três edições do Enade. No Quadro 1 é possível identificar as classificações analisadas pelo artigo para elucidar o cenário foco do estudo.

\begin{tabular}{ll}
\hline \multicolumn{1}{c}{ Variável } & \multicolumn{1}{c}{ Classificações } \\
\hline \hline Ano do Enade & 2006,2009 e 2012 \\
\hline Organização & Universidade \\
\hline Dependência Administrativa & Privada \\
\hline Área & Administração \\
\hline Conceito Enade Faixa & Sem Conceito (SC), 1, 2, 3, 4 ou 5 \\
\hline Categoria Administrativa & Com fins lucrativos, sem fins lucrativos, Especial \\
\hline "Subcategorias" das sem fins lucrativos & Comunitária, Confessional, Filantrópica \\
\hline
\end{tabular}

Quadro 1 Variáveis e observações analisadas pelo artigo.

Fonte: Baseado em Inep (2014).

Vale destacar que foram encontradas inconsistências de dados com relação às subcategorias no banco de dados do Inep (2014), de modo que se fez necessária uma pesquisa mais apurada com relação às informações disponibilizadas pelas próprias IES.

Para fins de estruturação da análise, optou-se pelos gráficos de barras e colunas, de modo que fosse possível estabelecer uma comparação direta entre a representação que cada categoria e subcategoria têm na amostra e o desempenho que apresentou nas edições do Enade. Tabelas foram incluídas para que valores absolutos pudessem ser evidenciados, demonstrando a grandeza do cenário a ser analisado.

\section{ANÁLISE DE RESULTADOS}

Na Tabela 1 o universo da pesquisa é apresentado em valores absolutos. Assim,a diminuiçãodo quantitativo de cursos de administração cadastrados na última edição do Enade, 


\section{UNIVERSIDADES PRIVADAS E O ENADE: QUAL CATEGORIA ADMINISTRATIVA TEM MELHOR \\ DESEMPENHO NO CURSO DE ADMINISTRAÇÃO \\ DOI: http://dx.doi.org/10.5007/1983-4535.2016v9n1p1}

presente tanto nas IES especiais como nas sem fins lucrativos, resulta em redução nas ofertas de vagas nestas duas categorias administrativas. Note que, para fins de avaliação, cada campus tem um cadastro no Enade; logo, os dados não podem ser confundidos com o número de universidades privadas existentes no Brasil.

Tabela 1 Quantidade de cadastros de universidades privadas nas três edições do Enade.

\begin{tabular}{|c|c|c|c|}
\hline \multirow{2}{*}{ Categoria Administrativa } & \multicolumn{3}{|c|}{ Edição do Enade } \\
\hline & 2006 & 2009 & 2012 \\
\hline Com fins lucrativos & 45 & 52 & 52 \\
\hline Sem fins lucrativos & 195 & 213 & 172 \\
\hline Especial & 28 & 29 & 18 \\
\hline TOTAL & 268 & 294 & 242 \\
\hline
\end{tabular}

Em se tratando da qualidade do ensino ofertado, preocupação maior dos sistemas de avaliação criados e deste artigo, foram elaborados os Gráficos 2 e 3, que consideram os resultados nas três edições do Enade das universidades privadas com, sem fins lucrativos e especial. Categorias estas que hoje podem ser facilmente avaliadas, analisadas e comparadas, na medida em que foram aferidos conceitos a todos os cursos ofertados, segundo a última edição do Enade.

Considerando que o resultado 3 no Enade representa o nível mínimosatisfatório de qualidade esperado para os cursos de graduação, o resultado das IES com fins lucrativos levanta preocupação, na medida em que quase $50 \%$ dos cursos ofertados apresentaram em 2012 desempenho abaixo do nível mínimo esperado. Em outras palavras, é significativa a quantidade de cursos ofertados por esta categoria administrativa que apresenta dificuldade em desenvolver as habilidades requeridas para que os estudantes possam atuar como profissionais competentes em sua área.

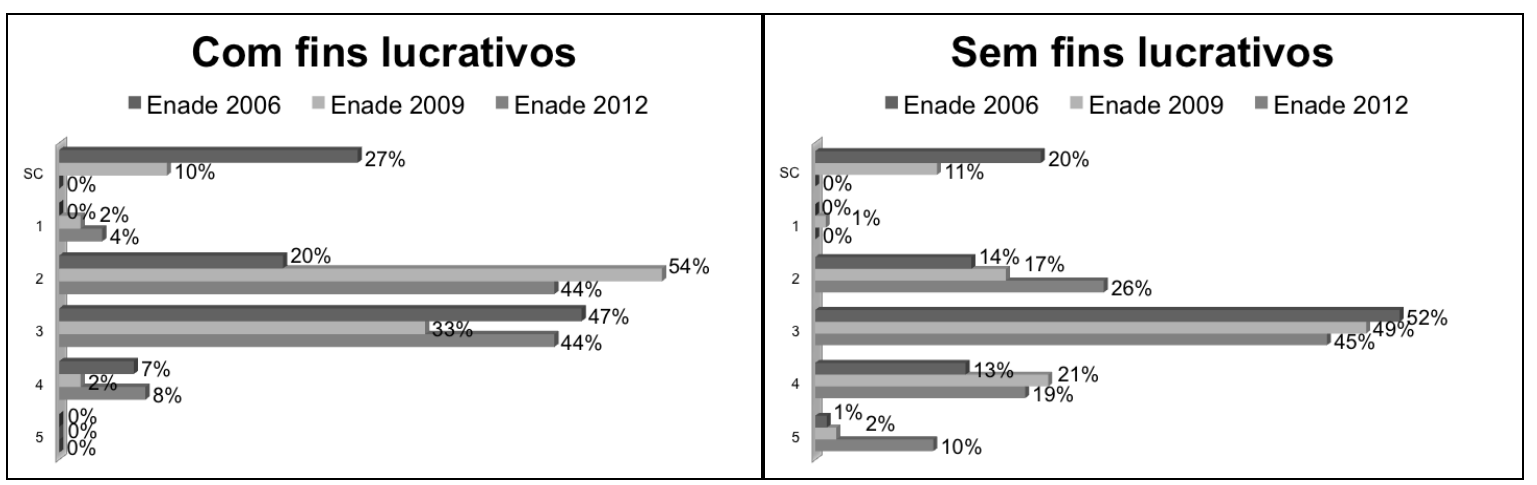

Gráfico 2 Desempenho nas três edições do Enade das universidades privadas com e sem fins lucrativos. 
Por outro lado, as universidades privadas sem fins lucrativos mantêm mais de $70 \%$ das ofertas não só com qualidade, mas como também teve um salto de participação no nível 5 , considerado de excelência. Na categoria especial acontece uma situação semelhante, onde mais de $70 \%$ apresentam qualidade satisfatória, apesar da perda de representatividade no nível 5, compensada pelo aumento de sua participação no nível 4, conforme Gráfico 3.

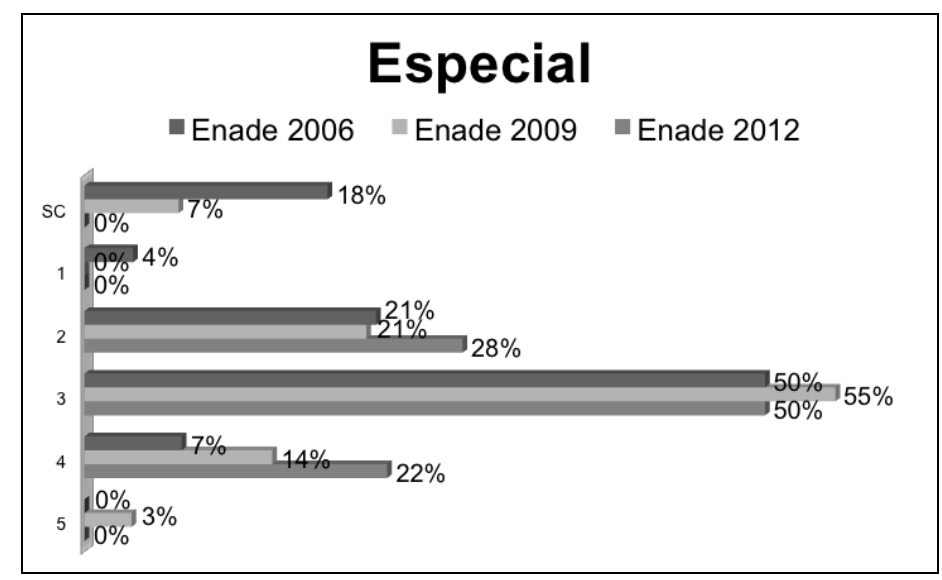

Gráfico 3 Desempenho nas três edições do Enade das universidades privadas especiais.

Em virtude das especificidades das subcategorias que compõe as IES sem fins lucrativos, o presente estudo se preocupou em identificar o desempenho nas três edições do Enade de cada categoria e subcategoria administrativa. Assim, ao comparar a participação no exame das comunitárias, confessionais e não comunitárias ou confessionais, conforme Gráfico 4, nota-se uma constância na participação de cada subcategoria.

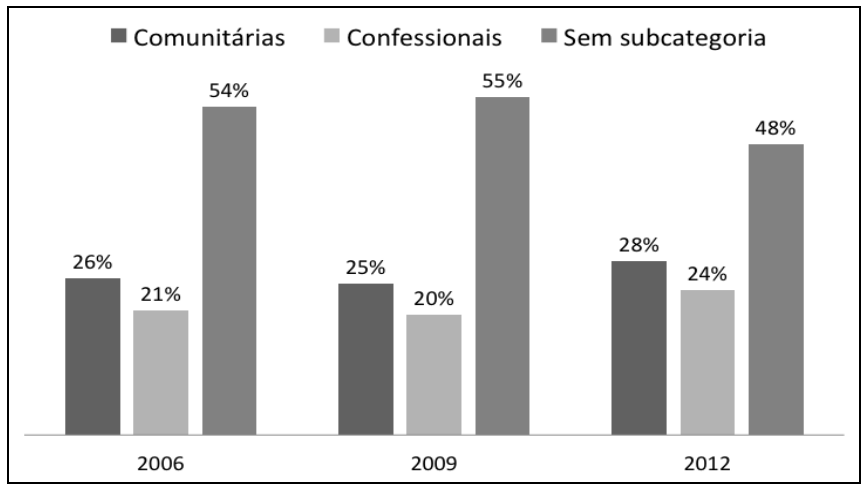

Gráfico 4 Frequência relativa das universidades privadas sem fins lucrativos comunitária, confessional e sem subcategoria (não comunitária ou confessional).

No que se refere a qualidade do curso ofertado, o Gráfico 5 apresenta o desempenho das comunitárias e confessionais. Neste caso, é notório que as de cunho social apresentam, 
mesmo após a inclusão de todos os cadastros em categorias com conceito, resultados que indicam pouco mais de $30 \%$ destas IES em níveis abaixo do mínimo satisfatório, o que pode levantar dúvidas acerca da qualidade dos cursos ofertados; por outro lado, as de cunho religioso tiveram um desempenho bem mais favorável no Enade, pois somente $15 \%$ destas instituições obtiveram resultados 1 e 2 .

Somado a este resultado, o aumento da representação dos cursos oferecidos pelas confessionais nos níveis considerados de excelência no exame (conceitos 4 e 5), trás à discussão a possibilidade de que o fato de atuar com base em doutrinas religiosas possa ser um fator positivo no provimento de um ensino de qualidade, segundo os parâmetros definidos pelo Sinaes.

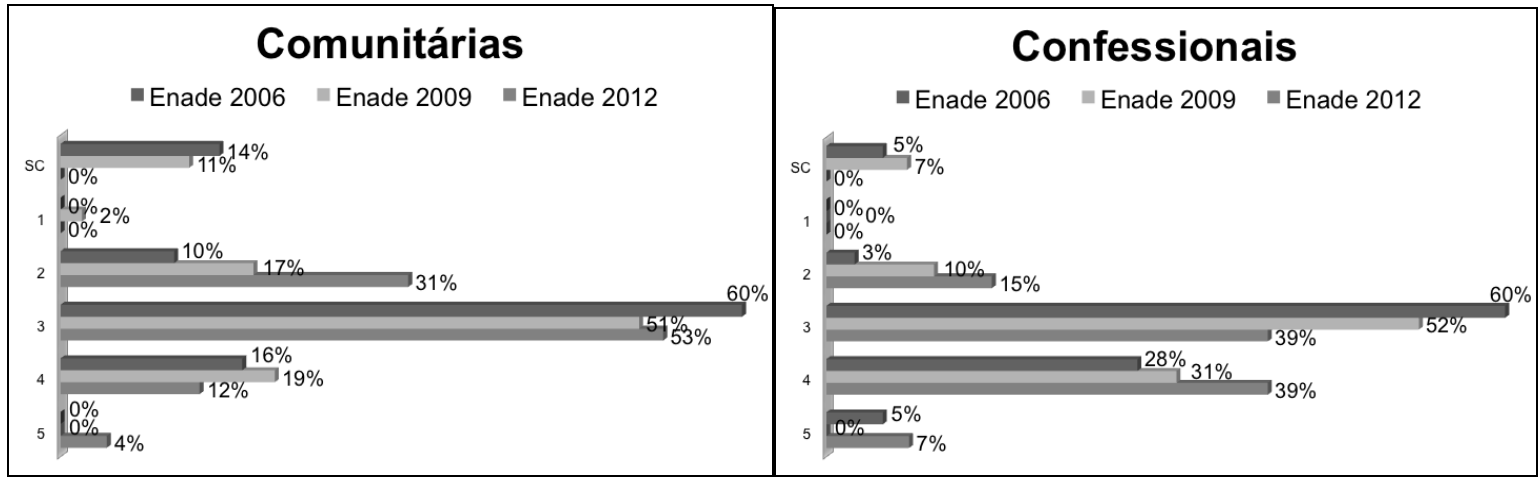

Gráfico 5 Desempenho nas três edições do Enade das universidades privadas sem fins lucrativos comunitária e confessional.

Não menos importante é relatar o caso das IES não comunitárias ou confessionais (sem subcategoria), uma vez em que representam aproximadamente metade da amostra. No Gráfico 6 é possível verificar o desempenho no Enade deste tipo de universidade privada, que assim como as confessionais, vem melhorando a qualidade dos cursos ofertados, mas que, por outro lado, ainda apresenta $30 \%$ dos cursos em administração não satisfazendo o nível mínimo de qualidade exigido, sendo neste aspecto, semelhante às comunitárias. Novamente, é válido questionar se a ausência de doutrina religiosa ou o cunho social vem influenciando o desempenho acadêmico destas IES. 


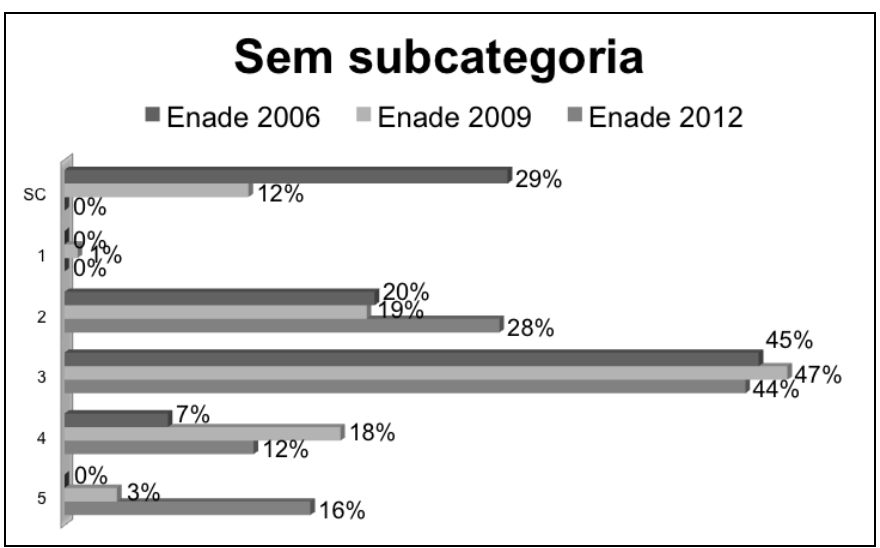

Gráfico 6 Desempenho nas três edições do Enade das universidades privadas sem fins lucrativos sem subcategoria (não comunitária ou confessional).

Por fim, com relação a subcategoria filantrópica, realidade de mais de $70 \%$ das universidades privadas sem fins lucrativos que oferecem o curso de administração (Gráfico 7), os resultados sugerem que sua ausência tem impacto direto na qualidade do curso ofertado.

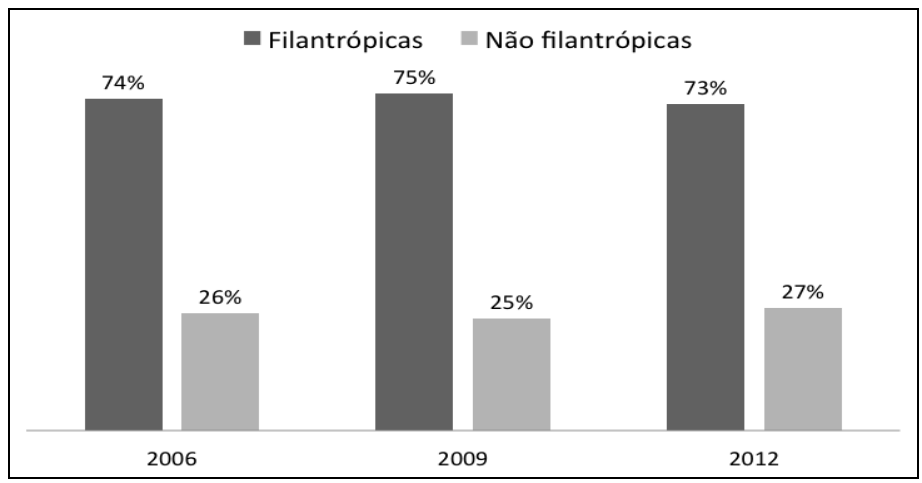

Gráfico 7 Frequência relativa das universidades privadas sem fins lucrativos filantrópicas e não filantrópicas.

No gráfico 8 , a constatação de que 43\% das não filantrópicas se encontram no nível 2 na edição do Enade de 2012, parece ser, um dado irrefutável a favor da maior qualidade na formação profissional de nível superior que é oferecida pela filantropia, não sendo, porém, objeto desse estudo investigar as possíveis causas desta realidade. 


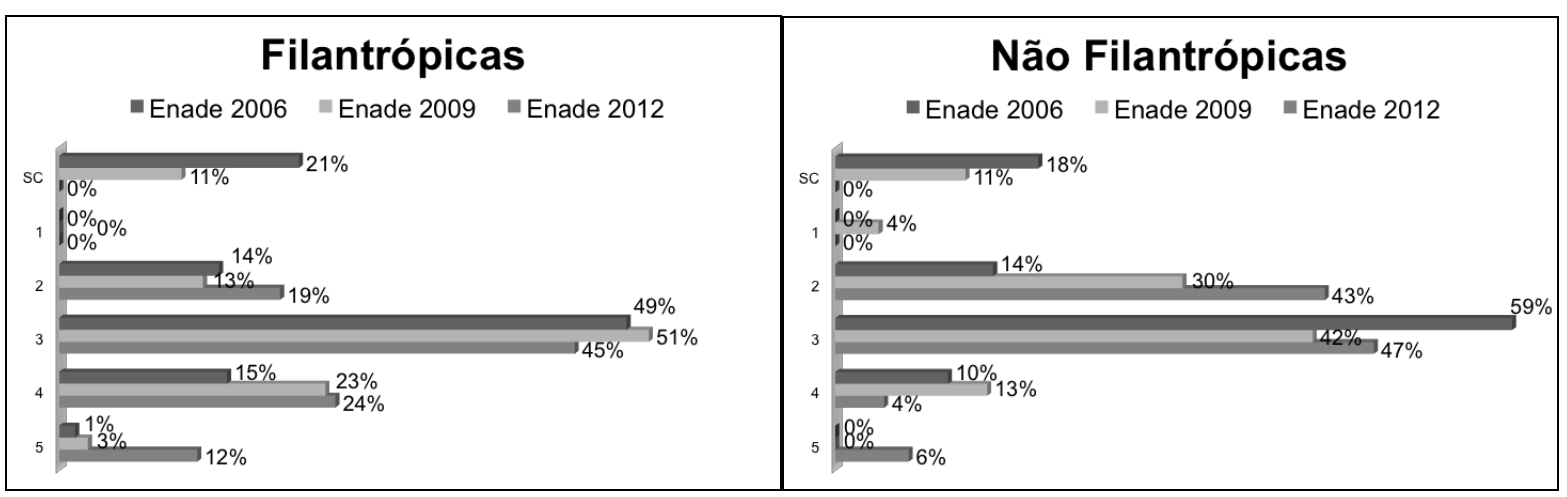

Gráfico 8 Desempenho nas três edições do Enade das universidades privadas sem fins lucrativos filantrópicas e não filantrópicas.

\section{CONSIDERAÇÕES FINAIS}

Ao estudar as universidades privadas, alguns aspectos particulares chamaram a atenção, pois, após todos os cursos ofertados serem incluídos em categorias com conceito, o que facilitou a avaliação, comparação e análise, a redução no número de ofertas em IES sem fins lucrativos e especiais trouxe dúvidas quanto ao impacto que tais categorias estão tendo na sobrevivência das mesmas. Ainda assim, a proporcionalidade mantida entre a representação das subcategorias - comunitária, confessional e filantrópica - impossibilitaram os autores de inferir qualquer relação entre tais informações.

De qualquer forma, ficou a percepção de que a pressão para ter lucros pode estar desviando as atenções dos gestores das IES com fins lucrativos de um fator que impacta diretamente na sobrevivência dos cursos: a qualidade do ensino. Apresentar quase $50 \%$ das ofertas em níveis abaixo do mínimo satisfatório está longe de ser orgulho para este tipo de organização. E se não ter fins lucrativos ou ser especial é uma forma de colocar o dinheiro no seu devido lugar, como meio e não fim da proposta, os resultados corroboram que esta postura pode e deve ser repetida na busca por um aumento consistente na qualidade.

Não obstante, a ausência de cunho social ou doutrina religiosa demonstra posições dispersas, enquanto que o contrário traz consigo força nas ações promovidas por estas organizações. E não se pode desconsiderar o fato de que este tipo de organização, ao investir em hospitais universitários, escolas e atendimento a população carente, garante ganhos para a sociedade que ultrapassam a qualidade ofertada no processo educacional. Ainda assim, as confessionais demonstram resultados ainda mais positivos e um aumento consistente de qualidade que as comunitárias não conseguiram demonstrar. 
No que tange a filantropia, é certo que a consistência na qualidade foi demonstrada por este tipo de IES, que auxiliam o Estado e atendem a população com serviços essenciais. Por outro lado, os cursos oferecidos pelas universidades privadas sem fins lucrativos e não filantrópicas apresentam baixo desempenho no Enade, o que leva a questionamentos quanto a sua capacidade de aferir competência nos estudantes para atuarem como profissionais no futuro próximo.

Assim, no quadro geral apresentado pelo artigo, são encontrados indícios que podem contribuir para a dedução de que características como a ausência de fins lucrativos, a orientação confessional e a filantropia, favorecem o nível de qualidade nos cursos de administração. Contudo, são necessárias novas investigações em um futuro trabalho para que se possa conhecer os fatores que motivam estes resultados positivos na Avaliação do Enade.

\section{REFERÊNCIAS}

AMARAL, N. C. Financiamento da educação superior: Estado x Mercado. São Paulo: Cortez Editora, 2003.

ARAUJO, Neiva Cristina de. Universidades comunitárias como propulsoras da efetivação dos direitos humanos: uma análise a partir da experiência da Unijuí. Direito em debate.

Revista do departamento de ciências jurídicas e sociais da Unijuí. Ano XIX n. 33, jan.-jun. 2010. n. 34, jul.-dez. 2010. Disponível em:

$<$ https://www.revistas.unijui.edu.br/index.php/revistadireitoemdebate/article/viewFile/623/34 8$>$. Acesso em: 15 jun. 2015.

BITTENCOURT, H. R.; VIALI, L.; CASARTELLI, A. de O.; RODRIGUES, A. de O. Uma análise da relação entre os conceitos Enade e IDD.Estudos em Avaliação Educacional. São Paulo, v.19, n.40, p.247-262, 2008. Disponível em:

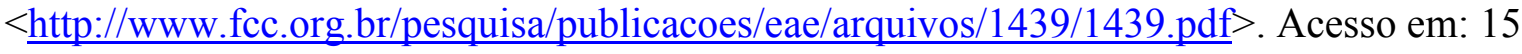
jun. 2015.

BRASIL, Ministério da Educação e do Desporto. Lei n ${ }^{\circ}$ 9.131, de 24 de novembro de 1995. Brasília, D.O.U., 1995. Disponível em:

$<$ http://www.planalto.gov.br/ccivil 03/leis/19131.htm>. Acesso em: 15 jun. 2015.

. Lei $n^{\circ}$ 9.394, de 20 de dezembro de 1996. Brasília, D.O.U., 1996. Disponível em: $<$ http://www.cp2.g12.br/alunos/leis/lei diretrizes ba ses.htm $>$. Acesso em: 15 jun. 2015.

. Lei $n$ 9.870, de 23 de novembro de 1999. Brasília, D.O.U., 1999. Disponível em: <http://www.planalto.gov.br/ccivil 03/leis/L9870.htm\#art9>. Acesso em: 15 jun. 2015.

Lei $n^{0} 10.861$, de 14 de abril de 2004. Brasília, D.O.U., 2004. Disponível em: $\overline{<\mathrm{http}}$ ://www.planalto.gov.br/ccivil_03/ato2004-2006/2004/lei/110.861.htm>. Acesso em: 15 jun. 2015. 
. Decreto n. 5.773/06. Brasília, D.O., 2006. Disponível em:

$<$ http://www.planalto.gov.br/ccivil 03/ ato2004-2006/2006/decreto/d5773.htm $>$. Acesso em: 15 jun. 2015.

. Portaria Normativa 4, de 5 de agosto de 2008. Conceito Preliminar dos Cursos Superiores (CPC). Brasília, D.O., 2008. Disponível em: $<$ http://download.inep.gov.br/download/superior/condicoesdeensino/Portaria_N_4_de 5 de agosto_2008.pdf>. Acesso em: 15 jun. 2015.

. Portaria Normativa 12, de 5 de setembro de 2008. Índice Geral de Cursos da Instituição de Educação Superior (IGC). Brasília, D.O., 2008. Disponível em: $<\underline{\text { http://download.inep.gov.br/download/superior/condicoesdeensino/PORTARIA_NORMATI }}$ VA_12.pdf $>$. Acesso em: 15 jun. 2015.

Lei n. 12.101/09.Brasília, D.O., 2009. Disponível em: $\overline{<\mathrm{http}}$ ://www.planalto.gov.br/ccivil 03/ ato2007-2010/2009/lei/112101.htm>. Acesso em: 15 jun. 2015.

BRITTO, Luiz Percival Leme; SILVA, Edineuza Oliveira; CASTILHO, Katlin Cristina de;ABREU, Tatiane Maria. Conhecimento e formação nas IES periféricas perfil do aluno "novo" da educação superior. Revista da Avaliação da Educação Superior, Campinas;Sorocaba, SP, v. 13, n. 3, p. 777-791, nov. 2008.

DCE - Divisão de Temas Educacionais. Universidades. Disponível em: $<$ http://www.dce.mre.gov.br/IES.php $>$. Acesso em: 15 jun. 2015.

Denominações de Instituições de Ensino Superior. Disponível em:

$\overline{<\mathrm{http}}$ ://www.dce.mre.gov.br/nomenclatura cursos.html $>$. Acesso em: 15 jun. 2015.

DIAS SOBRINHO, José. Avaliação e transformações da educação superior brasileira (19952009): do provão ao Sinaes. Revista da Avaliação da Educação Superior, Campinas; Sorocaba, SP, v. 15, n. 1, p. 195-224, mar. 2010. Disponível em:

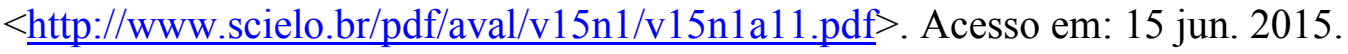

FRAUCHES, Celso. Educação Superior Comentada - políticas, diretrizes, legislação e normas do ensino superior. Mantenedoras de IES: constituição e alterações. 04 jun. 2012. Associação Brasileira de Mantenedoras de Ensino Superior (ABMES). Ano 2. n. 59.28 mai. A 4 jun. 2012. Disponível em: <http://www.abmes.org.br/abmes/noticias/detalhe/id/541>. Acesso em: 15 jun. 2015.

GARCIA, Adriana Amadeu; NICOLINI, Alexandre Mendes; ANDRADE, Rui Otávio Bernardes de. Valor agregado aos estudantes nos cursos de administração: uma comparação do desempenho entre instituições de ensino superior públicas e privadas. Revista GUAL Revista Gestão Universitária na América Latina. Florianópolis, v. 7, n. 2, p. 24-46, mai. 2014. Disponível em: $<$ http://www.redalyc.org/articulo.oa?id=319331138002>. Acesso em: 15 jun. 2015. 
INEP - Instituto Nacional de Estudos e Pesquisas Educacionais Anísio Teixeira. Sinopses estatísticas da educação superior - graduação. 2012. Disponível em:

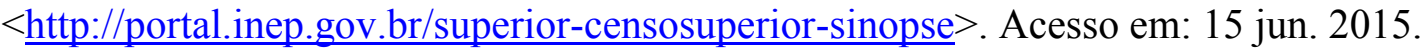
$\overline{2015}$.

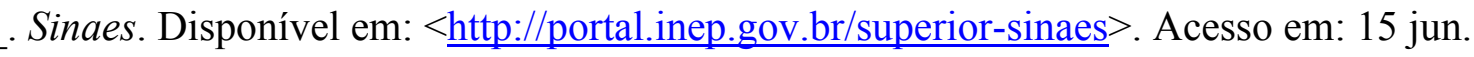

LIMA, Anesio Aparecido.Universidade comunitária no Brasil: a busca por uma identidade. Universidade de Sorocaba (UNISO). Orientador: José Dias Sobrinho. Sorocaba, set. 2009. Disponível em:

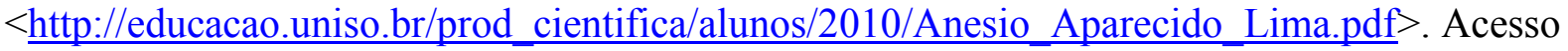
em: 15 jun. 2015.

MEC - Ministério da Educação e Cultura. Qualidade da Educação Superior. Livreto. 2013. Disponível em: $<$ http://portal.mec.gov.br>. Acesso em: 15 jun. 2015.

NICOLINI, Alexandre Mendes; ANDRADE, Rui Otávio Bernardes de; TORRES, Adriana Amadeu Garcia. Comparando os resultados do Enade 2009 por número de instituições e número de estudantes: como anda o desempenho acadêmico dos cursos de administração. Administração: Ensino e Pesquisa. Rio de Janeiro, v. 14, n. 1, p. 161-196, Jan./Fev./Mar. 2013. Disponível em: $<$ http://old.angrad.org.br/revista/edicoes_anteriores/57/>. Acesso em: 15 jun. 2015.

O ENSINO SUPERIOR PRIVADO, UMA ANÁLISE COMPARATIVA: RS E SP. Ensaios FEE - Fundação de Economia e Estatística. $5^{\circ}$ Encontro de Economia Gaucha (EEG). Jun. 2011. Disponível em: $<$ http://cdn.fee.tche.br/eeg/5/67.doc $>$. Acesso em: 15 jun. 2015.

SÉCCA, Rodrigo Ximenes; LEAL, Rodrigo Mendes. Análise do setor de ensino superior privado no Brasil. BNDES 2009. Disponível em:

$<$ http://www.bndes.gov.br/SiteBNDES/bndes/bndes pt/Institucional/Publicacoes/Consulta E xpressa/Setor/Educacao/200909_03.html>. Acesso em: 15 jun. 2015.

Semerj - Sindicato das Entidades Mantenedoras dos Estabelecimentos de Ensino Superior do Estado do Rio de Janeiro. Panorama do Ensino Superior no Estado do Rio de Janeiro 2015.

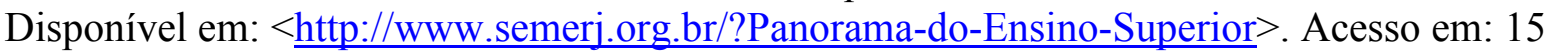
jun. 2015.

TANEGUTI, Luiza Yoko. Projeto CNE/UNESCO 914BRZ1136.3: Desenvolvimento, aprimoramento e consolidação de uma educação nacional de qualidade. Brasília: MEC/CNE 04 jun. 2013. Disponível em:

$<$ http://portal.mec.gov.br/index.php?option=com docman\&task $=$ doc download\&gid $=13948$

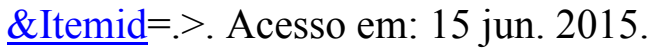

TAVARES, Sergio Marcus Nogueira. Governança em universidades confessionais no Brasil: modelo em construção. Educação \& Linguagem. v. 12. n. 19. Jan.-jun. 2009. Disponível em: $<$ https://www.metodista.br/revistas/revistas-ims/index.php/EL/article/viewFile/823/890>. Acesso em: 15 jun. 2015. 
. As universidades confessionais brasileiras e as reformas da educação superior da década de 1990. Universidade Federal de São Carlos. Programa de Pós-Graduação em Educação. Tese de Doutorado. São Carlos - SP. 2012. Disponível em:

$<\underline{\text { http://www.cogeime.org.br/wp-content/uploads/2012/11/As-Universidades-Confessionais- }}$ Brasileiras-e-as-Reformas-da-Educa $\% \mathrm{C} 3 \% \mathrm{~A} 7 \% \mathrm{C} 3 \% \mathrm{~A} 30-S u p e r i o r-d a-D \% \mathrm{C} 3 \% \mathrm{~A} 9$ cada-de1990.pdf $>$. Acesso em: 15 jun. 2015.

VERHINE, Robert Evan; DANTAS, Lys Maria Vinhaes; SOARES, José Francisco. Do Provão ao ENADE: uma análise comparativa dos exames nacionais utilizados no Ensino Superior Brasileiro. Revista Ensaio: avaliação de políticas públicas educacionais. v. 14, n. 52, p. 291-310. Rio de Janeiro: jul./set. 2006. Disponível em: $<\underline{\text { http://www.scielo.br/pdf/en }}$

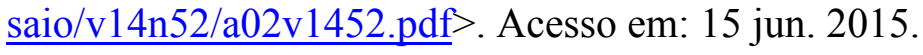

